\title{
MODELAGEM DA DISPERSÃO DE POLUENTES ATMOSFÉRICOS PARA AVALIAÇÃO DA QUALIDADE DO AR EM SÃO JOSÉ DA LAPA/MG
}

\author{
RIBEIRO, Marcos Vinicius - mvribeiro@ymail.com \\ Centro Universitário Newton Paiva
}

\author{
FERREIRA, Thaysa Karolyne Aguiar - thaysakaf@gmail.com \\ Centro Universitário Newton Paiva
}

\author{
SANTOS, Jasmin Dias dos - jasmimdsantos@gmail.com \\ Centro Universitário Newton Paiva
}

\begin{abstract}
RESUMO: A área objeto de estudo deste trabalho é o município de São José da Lapa em Minas Gerais. Devido ao seu relevo cárstico, essa área é fortemente explorada por 2 mineradoras, aqui tratadas como A e B, que trabalham com beneficiamento de calcário. Os dados referentes às emissões de Partículas Totais em Suspensão (PTS) foram obtidos na Fundação Estadual do Meio Ambiente, a seguir elaborou-se a modelagem através do software AERMOD para estudo da dispersão através de 2 cenários (inverno e verão), que correspondem ao período de maior seca (junho a setembro) e de maior pluviosidade (dezembro a fevereiro). As modelagens foram realizadas para todo o ano de 2016, considerando a emissão máxima diária e a média de cada período estudado. No cenário mais crítico que é a emissão máxima em 24 horas, a modelagem mostra a maior concentração verificada que é $151,1 \mu \mathrm{g} / \mathrm{m}^{3}$ - valor que ultrapassa o padrão secundário definido para PTS, de acordo com a resolução do CONAMA 03/90. Os resultados indicam a necessidade de ações mais incisivas para o controle da poluição atmosférica local, propõe-se a aspersão mais frequente de água, adensamento da cortina arbórea ao redor das mineradoras e implantação de tecnologias mais efetivas nos fornos de calcinação, na tentativa de reduzir as emissões destes poluentes. A modelagem mostrou-se uma ferramenta bastante interessante para estudos de avaliação da qualidade do ar.
\end{abstract}

Palavras-chave: Modelagem, AERMOD, dispersão, qualidade do ar

ATMOSPHERIC POLLUTANTS DISPERSION MODELING FOR AIR QUALITY ASSESSMENT IN SÃO JOSÉ DA LAPA/MG

ABSTRACT: The studied area is the municipality of São José da Lapa in Minas Gerais. Due to its karst relief, this area is heavily exploited by 2 miners, here treated as $A$ and $B$, that work with limestone processing. The data concerning the emissions of Total Suspended Particles (PTS) were obtained from the State Environmental Agency. Then the modeling was developed through the AERMOD software to study the dispersion through 2 scenarios (Winter and Summer), which correspond to the period of greater drought (June to September) and of greater rainfall (December to February). The modeling was performed for the entire year of 2016, considering the maximum daily emission and the average of each period studied. In the most critical scenario, that is the maximum emission in 24 hours, the modeling shows the highest verified concentration that is 151.1 $\mu \mathrm{g} / \mathrm{m}^{3}$ - a value that exceeds the secondary standard defined for PTS, according to CONAMA Resolution 03/90. The results indicate the need for more incisive actions to control local air pollution, it is proposed to more frequent sprinkling of water, densification of the curtain around the miners and implantation of more effective technologies in the calcination furnaces, in an attempt to reduce emissions of these 
pollutants. The modeling has proved to be a very interesting tool for air quality evaluation studies.

Keywords: modeling, AERMOD, dispersion, air quality

\section{INTRODUÇÃO}

O crescimento populacional e industrial, e consequente formação de centros urbanos cada vez maiores, fazem com que a poluição atmosférica seja crescente na sociedade contemporânea. Dessa forma, "a degradação da qualidade do ar pode causar sérios problemas à condição de vida das pessoas e ecossistemas" (JACOMINO et al, 2009).

A área objeto de estudo deste trabalho é o município de São José da Lapa, cidade que se localiza na região metropolitana de Belo Horizonte. Devido ao seu relevo cárstico, essa área é fortemente explorada por 2 mineradoras, aqui tratadas como A e B, que trabalham com lavra e beneficiamento de calcário (Figura 1).

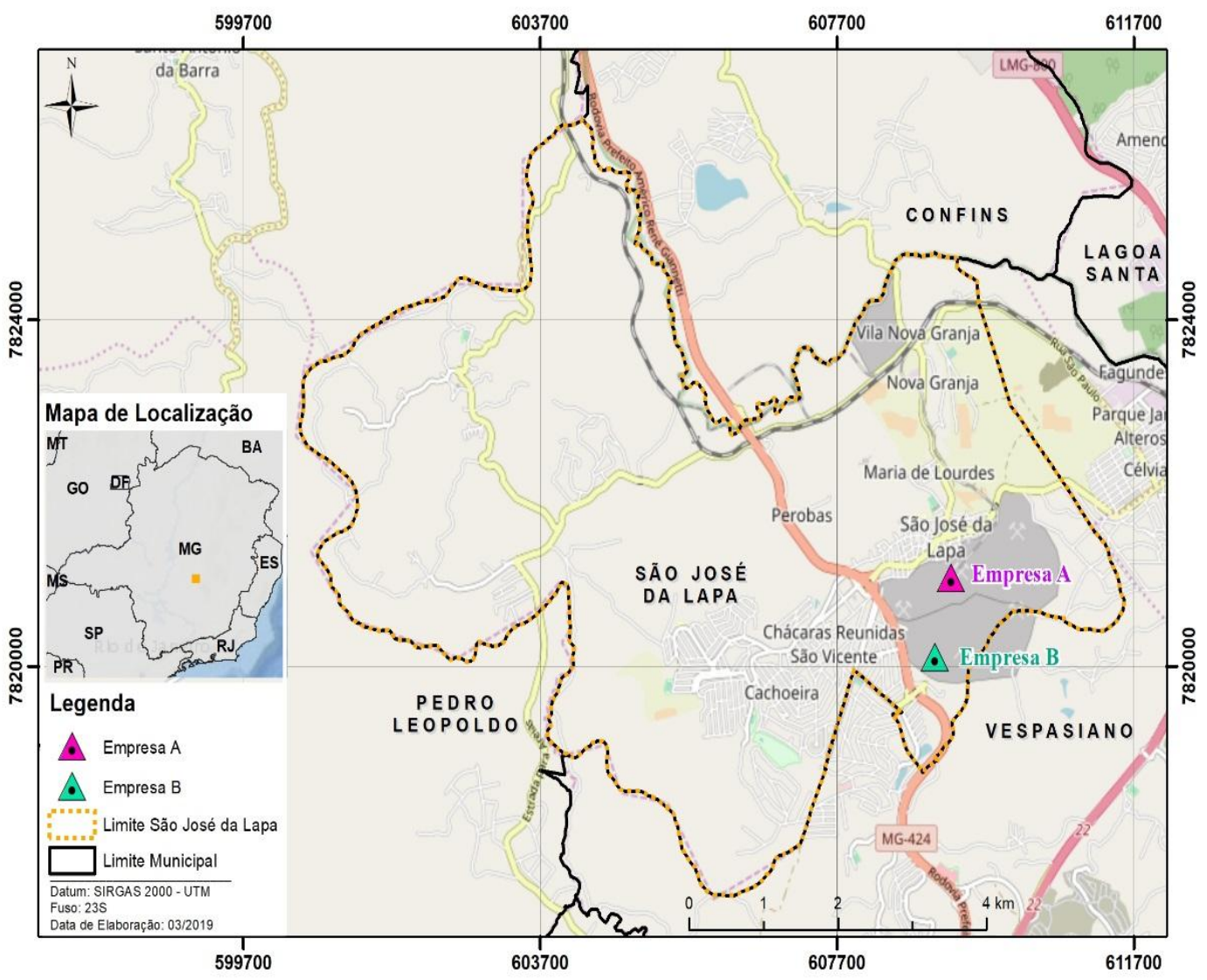

Figura 1 - Mapa de localização de São José da Lapa e alocação das empresas. A e B no município.Elaboração: Autores (2017)

As 2 empresas estão muito próximas entre si, desenvolvendo processos produtivos similares, incluindo ainda a produção de cales, processos de cominuição, movimentação, transporte, estocagem e calcinação de materiais (ECOSOFT, 2014). Sabe-se, então, que as emissões de poluentes atmosféricos 
são inerentes às atividades industriais destas duas empresas, sobretudo as emissões de material particulado tanto por fontes pontuais (chaminés), quanto por fontes difusas (fugitivas) (ECOSOFT, 2014). O ano escolhido para estudo foi 2016, devido a maior constância, disponibilidade e confiabilidade dos dados correspondentes a este período.

Este trabalho fundamentou-se, então, na importância da qualidade do ar na vida humana e no meio ambiente. Dessa forma, estudaram-se os parâmetros de qualidade do ar, conforme legislação do Conselho Nacional de Meio Ambiente (CONAMA), avaliando as contribuições das mineradoras no que tange à poluição atmosférica do referido munícipio. Além disso, sabendo que a qualidade do ar também é definida por parâmetros meteorológicos e topográficos (FEAM, 2016), tais fatores também foram estudados ao longo do desenvolvimento deste trabalho.

De forma a conhecer o impacto das duas mineradoras na qualidade do ar no município alvo de estudo, bem como avaliar a maneira pela qual a poluição atmosférica atua na região, foi executada a modelagem matemática da dispersão dos poluentes atmosféricos, através do software AERMOD, que possibilitou conhecer a amplitude da pluma de contaminação que atinge a região de estudo. Assim, utilizando a modelagem atmosférica, foi possível apontar melhorias para a gestão da qualidade do ar, visto que, conforme afirmado por Melo (2016), a modelagem torna possível o estabelecimento de causa-efeito, auxiliando, portanto, na compreensão da dinâmica atmosférica da região estudada.

\section{REFERENCIAL TEÓRICO}

\subsection{FUNDAMENTOS DA QUALIDADE DO AR}

De acordo com a Fundação Estadual de Meio Ambiente de Minas Gerais FEAM (2016), a qualidade do ar sofre interferência direta da distribuição e intensidade das emissões de poluentes atmosféricos provenientes de veículos (fontes móveis) e indústrias (fontes fixas). Contudo, conforme afirma a Companhia Ambiental do Estado de São Paulo - CETESB (2015), a topografia e as condições meteorológicas também têm papel fundamental quanto à classificação da qualidade do ar.

Segundo afirma Gomes (2010), p. 77:

$\mathrm{O}$ ar considera-se poluído uma vez que contenha um ou mais dos produtos considerados como "poluentes" em quantidades tais e durante um tempo suficientemente longo para que se manifestem efeitos nocivos ao nível do conforto e variedade dos seres vivos ou ao nível da conservação dos materiais, do clima, das culturas, etc.

A Agência de Proteção Ambiental dos Estados Unidos (USEPA, 2016) define que, geralmente, as emissões atmosféricas de origem antrópica são provenientes das seguintes fontes:

- Fonte de combustão estacionária, como serviços de eletricidade e caldeiras industriais; 
- Indústrias em seus mais variados seguimentos, como fundições de metais, refinarias de petróleo e fornos de cimenteiras;

- Automóveis e fontes móveis não-rodoviárias definidas como equipamento recreativos e de construção, navios e locomotivas.

Conforme Gomes (2010), a meteorologia determina o que acontece com os gases emitidos na atmosfera desde o momento em que estes são emitidos até quando são detectados em qualquer outro lugar. Segundo a FEAM (2016) apud Raia e Reis (2006) o relevo é um fator determinante na qualidade do ar de uma região. O autor diz que o relevo ondulado, formado por áreas de serra, como o de Minas Gerais, pode impactar de forma direta a dinâmica de alguns fenômenos climáticos, tais como a distribuição das chuvas, variação da temperatura, velocidade e direção dos ventos, entre outros.

\subsection{PADRÕES DE QUALIDADE DO AR E LEGISLAÇÃO}

Os padrões de qualidade do ar são regulamentados por legislações. Em âmbito Federal a Resolução no 03 de 28 de junho de 1990 do CONAMA é a responsável por determinar limites de emissões para alguns poluentes.

Segundo Guarieiro e Vasconcellos (2011), já foram identificados aproximadamente 3000 diferentes compostos na atmosfera, provenientes de ações antrópicas, o que torna inviável legislar sobre todos estes. Sendo assim, levando-se em consideração os prejuízos causados à saúde e ao meio ambiente, a Resolução CONAMA 03/90 define os limites máximos permitidos para os seguintes poluentes: Partículas Totais em suspensão (PTS), Partículas Inaláveis (PM10), Dióxido de Enxofre (SO2), Monóxido de Carbono (CO), Ozônio (O3), Dióxido de Nitrogênio (NO2) e Fumaça. A legislação referenciada define ainda que os poluentes atmosféricos devem atender padrões específicos de qualidade do ar, sendo eles (Resolução CONAMA n. 003, de 28 de jun. de 1990, p. 1):

I - Padrões Primários de Qualidade do Ar são as concentrações de poluentes que, ultrapassadas, poderão afetar a saúde da população.

II - Padrões Secundários de Qualidade do $\mathrm{Ar}$ são as concentrações de poluentes abaixo das quais se prevê o mínimo efeito adverso sobre o bem-estar da população, assim como o mínimo dano à fauna, à flora, aos materiais e ao meio ambiente em geral.

Sendo assim, os padrões secundários são os mais restritivos. A classificação dos padrões de qualidade do ar se dá ainda em poluente primário e secundário. Segundo a FEAM (2016), tal classificação é relativa quanto à origem desses poluentes. De acordo com este órgão ambiental, os poluentes primários são aqueles emitidos para a atmosfera diretamente de uma fonte, enquanto os poluentes secundários são oriundos de reações químicas que ocorrem na atmosfera (FEAM, 2016).

O principal poluente gerado pelas empresas analisadas são os materiais particulados advindos do beneficiamento mineral. Estes poluentes enquadramse no grupo das partículas totais em suspensão (PTS), visto que as mesmas 
versam em uma mistura de partículas sólidas e líquidas que exibem características químicas variadas, sendo que para a sua definição leva-se em conta as propriedades físicas do material (FEAM, 2016). Desta forma, os padrões os de qualidade do ar para as Partículas Totais em Suspensão (PTS), definidos pela legislação supracitada, estão expostos na Tabela 1.

Tabela 1- Padrões primários e secundários para emissão de Partículas Totais em Suspensão (PTS)

\begin{tabular}{c|cc}
\hline Legislação & \multicolumn{2}{c}{ Concentrações de PTS $\left(\boldsymbol{\mu g} / \mathbf{m}^{\mathbf{3}}\right)$} \\
& Diária & Anual \\
\hline Padrões Primários & 240 (média de & 80 (média \\
(CONAMA n⿳0 03/90) & 24 horas) & geométrica anual) \\
Padrões Secundários & 150 (média de & 60 (média \\
(CONAMA n⿳0 03/90) & 24 horas) & geométrica anual) \\
\hline
\end{tabular}

Fonte: Resolução CONAMA no 03 de 28 de Junho de 1990. Elaboração: FEAM, 2016. Adaptação: Autores (2017).

A média geométrica anual estabelece a concentração permitida para a emissão de poluentes em um ano, já a média horária estabelece limites para emissão de poluentes em 24 horas. A legislação permite que esses padrões sejam excedidos apenas uma vez ao ano.

\section{3 ÍNDICE DE QUALIDADE DO AR (IQAR)}

Os índices de qualidade do ar foram criados pela Agência de Proteção Ambiental dos Estados Unidos (USEPA, 2016). De acordo com a Fundação Estadual de Proteção Ambiental do Rio Grande do Sul (FEPAM, 2017), o Índice de Qualidade do Ar (IQAr) pode ser compreendido como uma ferramenta matemática capaz de converter valores numéricos de concentrações de poluentes em um valor adimensional que corresponde a um indicador que traduz o nível de poluição do ar. Segundo a FEAM (2016), a equação que define o IQAr é:

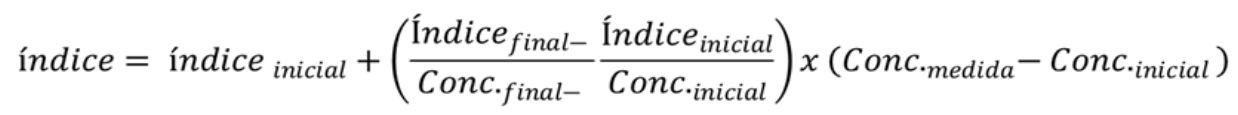

Onde:

Índice = Índice de qualidade do ar desejado;

Conc. medida $=$ Concentração medida

Conc. inicial $=$ Concentração inicial da faixa onde encontra-se a concentração medida;

Conc. final = Concentração final da faixa onde encontra-se a concentração medida;

Índice inicial = Valor do índice correspondente a Conc. inicial;

Índice final $=$ Valor do índice correspondente à Conc. final. 
Cada indicador possui uma cor correspondente (CETESB, 2015). A Tabela 2 apresenta a definição de cada índice, relacionando os mesmos com a concentração do poluente (FEAM, 2016) estudado neste trabalho, as partículas totais em suspensão (PTS). Segundo a USEPA (2017) a qualidade do ar de uma determinada região monitorada é definida pelo pior índice registrado durante aquele dia.

Tabela 2 - Índices de qualidade do ar e níveis de episódios críticos de poluição do ar

\begin{tabular}{|c|c|c|c|}
\hline \multicolumn{4}{|c|}{ Í́NDICES DE QUALIDADE DO AR } \\
\hline Qualidade & Índice & $\begin{array}{c}\text { Níveis de } \\
\text { Episódios } \\
\text { Críticos de } \\
\text { Poluição do } \\
\text { Ar }\end{array}$ & $\begin{array}{c}\text { PTS } \\
\text { Média de } \\
24 \text { horas } \\
\left(\mu \mathrm{g} / \mathrm{m}^{3}\right)\end{array}$ \\
\hline Boa & $0-50$ & & $0-80$ \\
\hline Regular & $51-100$ & & $81-240$ \\
\hline Inadequada & $101-200$ & Atenção & $241-375$ \\
\hline Má & $201-300$ & Alerta & $376-625$ \\
\hline Péssima & $301-400$ & \multirow{2}{*}{ Emergência } & $626-875$ \\
\hline Crítica & $401-500$ & & $876-1000$ \\
\hline
\end{tabular}

Fonte: Resolução CONAMA no 03 de 28 de Junho de 1990 e USEPA, 2016.Elaboração: GESAR/FEAM, 2016. Adaptação: Autores (2017).

\subsection{MODELAGEM DE DISPERSÃO DE POLUENTES}

O modelo matemático adotado no estudo de dispersão atmosférica é baseado na equação da pluma gaussiana. Esta equação assume que a dispersão do poluente de uma fonte com emissão contínua tem no ar atmosférico uma distribuição normal ao eixo da pluma, tanto no plano horizontal como no vertical (direção vertical z e direção y perpendicular à direção do vento) (Lakes Environmental Consultants, 2014).

Sendo assim, para o cálculo da concentração final de um determinado componente poluente em um determinado ponto, o modelo adota a seguinte equação:

$$
C(x, y, z)=\frac{F D}{2 \pi} \frac{Q}{u_{s} \sigma_{y} \sigma_{z}} \exp \left[\frac{-y^{2}}{2 \sigma_{y}^{2}}\right]\left\{\exp \left[\frac{-(z-h)^{2}}{2 \sigma_{z}^{2}}\right]+\exp \left[\frac{-(z+h)^{2}}{2 \sigma_{z}^{2}}\right]\right\}
$$

Onde:

$\mathrm{x}, \mathrm{y}=$ coordenadas cartesianas que identificam o ponto analisado;

z = altitude média da célula do ponto analisado, em relação ao nível do mar;

Q = taxa de emissão do poluente na fonte catalogada; 
us = velocidade média do vento na altura de emissão;

бy = parâmetro de distribuição na direção lateral ao eixo da pluma;

y = distância ortogonal ao eixo da pluma do ponto analisado à fonte emissora;

h = altura efetiva de emissão da fonte;

$\sigma \mathrm{z}=$ parâmetro de distribuição na direção vertical ao eixo da pluma;

$\mathrm{F}=$ fator de correção para diferentes tempos de amostragem;

D = termo de decaimento do poluente considerado.

As saídas oferecidas pelo software representam os resultados dos cálculos das concentrações no ar dos parâmetros de estudo, o que permite que sejam delimitados e visualizados em mapas os locais e áreas ao redor das fontes que potencialmente são afetados pelas emissões com alteração significativa da qualidade do ar da região (Lakes Environmental Consultants, 2014).

\section{METODOLOGIA}

Para a elaboração deste trabalho foi realizado um levantamento de referências bibliográficas sobre qualidade do ar e dispersão de poluentes atmosféricos. Dentre as bibliografias utilizadas, muniram-se de artigos científicos, relatórios de órgãos ambientais nacionais e internacionais, livros e legislações relacionados ao tema.

A dispersão de poluentes da área de estudo foi realizada a partir de modelagem matemática da dispersão dos poluentes atmosféricos emitidos pelas mineradoras alocadas na cidade de São José da Lapa. A modelagem foi executada através do software AERMOD da empresa Lakes Environmental Consultants Inc., operado em ambiente Windows. Para tanto, realizou-se o levantamento dos dados imputados no software, sendo eles:

1-Dados de emissão da fonte fixa (chaminés): Informações correspondentes à quantidade de poluentes emitidos pelas chaminés dos fornos das mineradoras em seus processos produtivos, bem como à caracterização das fontes fixas de poluição. Estes dados foram buscados na Superintendência Regional de Meio Ambiente Central Metropolitana (SUPRAM-CM), órgão ambiental para o qual os empreendedores fornecem o quantitativo de poluentes lançados na atmosfera, tornando-os de acesso público. Por meio de um pedido de vistas, teve-se acesso aos relatórios e estudos enviados pelas mineradoras ao órgão ambiental. 0 pedido de vistas foi solicitado sob os protocolos no R0206063/2017 e no R0206065/2017. Ressalta-se que para a construção da modelagem matemática deste trabalho, as fontes de emissões fugitivas não foram consideradas. Já as fontes fixas estudadas são aquelas de maior representatividade no que tange à carga poluidora emitida pelas mesmas, sendo estas as chaminés dos fornos das indústrias. As informações coletadas sobre tais fontes foram: altura, diâmetro e área das chaminés; vazão; velocidade e temperatura dos gases e taxas de emissão de material particulado. 
2-Dados meteorológicos: Compilação de informações em ferramentas online disponibilizadas pelo governo, através dos websites do Instituto Nacional de Meteorologia (INMET), do Instituo Nacional de Pesquisas Espaciais (INPE) e da Rede de Meteorologia do Comando da Aeronáutica (REDEMET). As informações climáticas compiladas correspondem a todo o ano de 2016, sendo dados diários e horários para todos os parâmetros requeridos para a execução da modelagem, sendo eles: temperatura, umidade, ponto de orvalho, pressão, velocidade e direção dos ventos, radiação, pluviosidade, cobertura de nuvem e altura da camada de mistura.

3-Informações do relevo da região: Para obtenção dos dados de relevo da região foi utilizado um Modelo Digital de Elevação (MDE). Trata-se da representação matemática/computacional contínua da topografia do terreno distribuída espacialmente às variações de altitude numa área baseada e definida sobre um plano cartográfico em um conjunto de coordenadas $X, Y$ e Z. O MDE em questão foi obtido através do website da Earth Explorer e foi tratado através do software ArcGIS, onde gerou-se uma nuvem de pontos com informações altimétricas e a mesma foi imputada no software AERMOD.

4-Para a caracterização da área de estudo, realizou-se pesquisas bibliográficas. Parte das informações adquiridas foram obtidas no Sistema Integrado de Informação Ambiental (SIAM), ferramenta online desenvolvida pelo governo estadual onde podem ser adquiridos estudos ambientais protocolados pelos empreendedores, contendo, entre outras informações, dados do relevo e das peculiaridades topográficas da área de estudo. Os estudos e relatórios obtidos na SUPRAM CM também foram utilizados na construção da caracterização da área.

A partir do levantamento de todos os dados mencionados, estes foram imputados e manipulados no software AERMOD. As modelagens foram realizadas considerando dois cenários: o de maior pluviosidade (verão) e o de maior seca (inverno). Para consolidar as análises, foi também elaborada a dispersão do poluente PTS para todo o ano de 2016. Para cada uma dessas modelagens realizadas, consideraram-se os dados de todo o período (média geométrica), bem como a máxima diária $(24 \mathrm{~h})$ do período, sendo que esta última leva em consideração o cenário mais crítico do tempo analisado.

Os dados pluviométricos do ano de 2016 foram utilizados para a identificação dos meses mais secos e mais chuvosos, visto que um dos objetivos é pontuar como ocorre a dispersão de poluentes nestes períodos do ano. As plumas de contaminação geradas, os produtos obtidos pelo software AERMOD, foram convertidas para a extensão shapefile (.shp), que possui informações das coordenadas geográficas da área, permitindo visualizar como a pluma de poluição atmosférica se comporta sobre o terrenos estudados. Estes arquivos gerados (shapefiles) foram adicionados ao software ArcGIS, que possibilitou a obtenção dos mapas locais associados ao comportamento da pluma de contaminação. 


\section{RESULTADOS E DISCUSSÕES}

\subsection{CARACTERIZAÇÃO DA ÁREA DE ESTUDO}

O município de São José da Lapa faz parte da região metropolitana de Belo Horizonte, estando a aproximadamente $28 \mathrm{~km}$ de distância da capital mineira. Segundo dados do Instituto Brasileiro de Geografia e Estatística - IBGE (2017) a população estimada em 2016 era de 22.592 habitantes.

Segundo a ECOSOFT (2014), Minas Gerais possui território majoritariamente planáltico, com altitude variando entre 100 a 1500 m, apresentando climas tropical e tropical de altitude. O município de São José da Lapa está a $700 \mathrm{~m}$ acima do nível do mar, constituindo uma região onde há ocorrência do clima tropical subsequente e semiúmido, com período seco de quatro a cinco meses (IBGE, 2005). "Este clima está associado principalmente à influência da altitude e do regime pluviométrico" (NIMER, 1989 apud ECOSOFT, 2014). Para o ano de 2016, elaborou-se o gráfico de precipitação (Figura 2), baseado nos dados de monitoramento da estação meteorológica do Aeroporto Internacional Tancredo Neves, localizado em Confins/MG, situado a aproximadamente $13 \mathrm{~km}$ de São José da Lapa/MG.

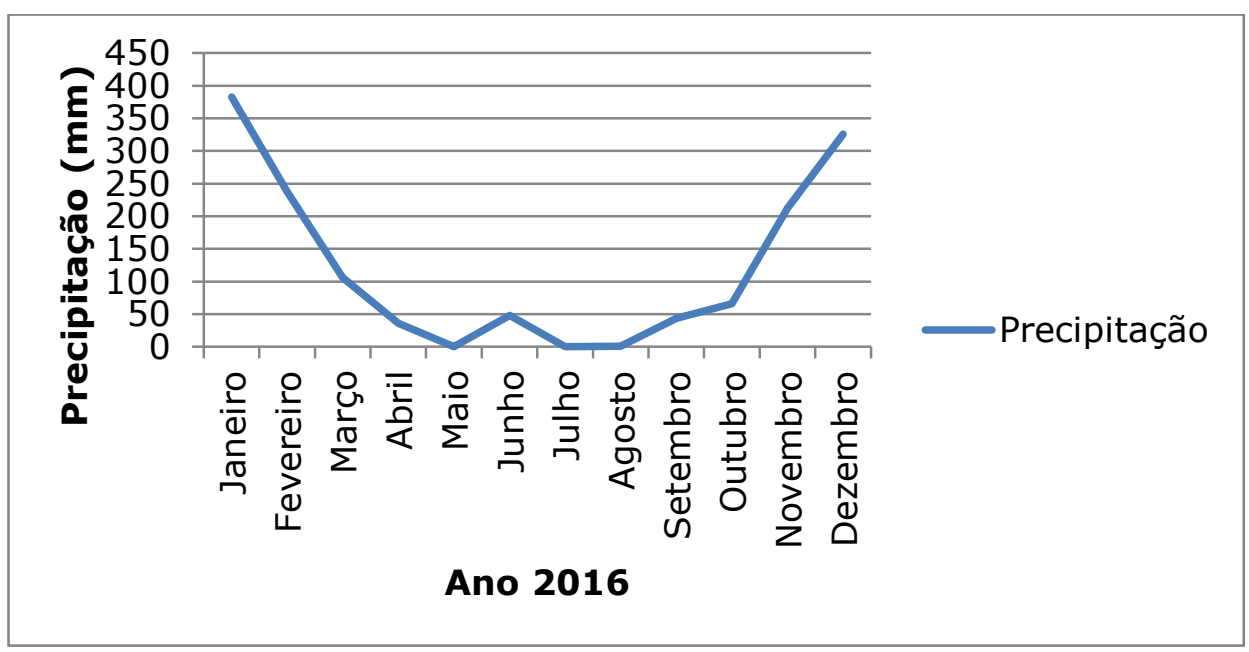

Figura 2 - Gráfico de precipitação no município de São José da Lapa para o ano de 2016. Fonte: Rede de Meteorologia do Comando da Aeronáutica (REDEMET). Elaboração: Autores (2017).

Como verifica-se através do gráfico (Figura 2), os maiores índices pluviométricos ocorrem no início (janeiro, fevereiro e março) e fim do ano (novembro e dezembro). Já nos meses de abril a outubro têm-se o período mais seco, sendo que os meses de inverno (junho, julho e agosto) apresentam as menores precipitações. Portanto, para a modelagem, o período de maior pluviosidade foi definido pelos meses de janeiro, fevereiro e março e o de maior seca pelos meses de junho, julho e agosto.

A região é atrativa para instalação de mineradoras, visto que seu relevo cárstico apresenta grande concentração de calcário, permitindo a produção de cal de boa qualidade (ECOSOFT, 2014). Dessa forma, há um representativo parque minerador instalado na região, liderado, majoritariamente, pelas empresas $A$ e $B$, sendo que estas fazem divisa entre si, desenvolvendo 
processos produtivos similares e, por conseguinte, produtos também de semelhantes características (ECOSOFT, 2014).

O processo produtivo da cal é potencialmente gerador de poluentes atmosféricos, principalmente de material particulado, que são emitidos por fontes fixas (chaminés) e fontes móveis (difusas). Outro ponto crítico em relação à atividade das mineradoras corresponde à localização das mesmas. Como pode ser visto na Figura 1, apresentada no início deste trabalho, o núcleo populacional da cidade encontra-se ao redor das mineradoras. Tal proximidade faz com que os impactos causados pelas atividades industriais destas duas empresas sejam fortemente sentidos pela população local, potencializando, assim, os impactos sociais nessa região.

\subsection{MODELAGEM MATEMÁTICA DA DISPERSÃO DO POLUENTE}

Para a construção da modelagem atmosférica da dispersão do material particulado emitido pelas duas empresas, devem-se conhecer as taxas de emissão deste poluente, as condições de relevo e meteorológicas da área. No que se refere aos dados de emissão atmosférica, para a construção da modelagem, utilizaram-se as informações adquiridas na SUPRAM-CM, conforme exposto na Figura 3.

\begin{tabular}{|c|c|c|c|c|c|c|c|c|c|c|c|}
\hline \multicolumn{12}{|l|}{ EMPRESA A } \\
\hline \multirow{2}{*}{ № Fonte } & \multirow{2}{*}{$\begin{array}{l}\text { Nome da } \\
\text { Fonte }\end{array}$} & \multicolumn{2}{|c|}{ Coordenadas } & \multirow{2}{*}{$\begin{array}{c}\begin{array}{c}\text { Altura } \\
\text { chaminé }\end{array} \\
m\end{array}$} & \multirow{2}{*}{$\begin{array}{c}\begin{array}{c}\text { Diâmetro } \\
\text { chaminé }\end{array} \\
\mathrm{m}\end{array}$} & \multicolumn{2}{|c|}{ Vazão } & \multirow{2}{*}{$\begin{array}{c}\begin{array}{c}\text { Velocidade } \\
\text { dos gases }\end{array} \\
\mathrm{m} / \mathrm{s}\end{array}$} & \multirow{2}{*}{\begin{tabular}{|c|}
$\begin{array}{c}\text { Temperatura } \\
\text { dos gases }\end{array}$ \\
${ }^{\circ} \mathrm{C}$ \\
\end{tabular}} & \multirow{2}{*}{$\begin{array}{c}\begin{array}{c}\text { Área da } \\
\text { chaminé }\end{array} \\
\mathrm{m}^{2}\end{array}$} & \multirow{2}{*}{$\begin{array}{c}\begin{array}{c}\text { Emissão } \\
\text { MP }\end{array} \\
\mathrm{kg} / \mathrm{h}\end{array}$} \\
\hline & & UTM $X$ & UTMY & & & $\mathrm{m}^{3} / \mathrm{h}$ & $\mathrm{Nm}^{3} / \mathrm{h}$ & & & & \\
\hline $\mathrm{CH} 1$ & FORNO A & 609247 & 7821095 & 55 & 3,3 & 235664,14 & 132369,11 & 7,60 & 161,87 & 8,553 & 16,1 \\
\hline $\mathrm{CH} 2$ & FORNO B & 609258 & 7821084 & 55 & 4,0 & 416482,68 & 229325,26 & 9,19 & 170,64 & 12,566 & 22,9 \\
\hline $\mathrm{CH} 3$ & FORNO C & 609365 & 7821076 & 55 & 1,2 & 72440,062 & 46694,153 & 17,76 & 104,41 & 1,131 & 4,9 \\
\hline \multicolumn{12}{|l|}{ EMPRESA B } \\
\hline \multirow{2}{*}{ № Fonte } & \multirow{2}{*}{$\begin{array}{l}\text { Nome da } \\
\text { Fonte }\end{array}$} & \multicolumn{2}{|c|}{ Coordenadas } & $\begin{array}{c}\text { Altura } \\
\text { chaminé }\end{array}$ & \begin{tabular}{|c|} 
Diâmetro \\
chaminé
\end{tabular} & \multicolumn{2}{|c|}{ Vazão } & $\begin{array}{c}\text { Velocidade } \\
\text { dos gases }\end{array}$ & $\begin{array}{c}\text { Temperatura } \\
\text { dos gases }\end{array}$ & $\begin{array}{l}\text { Área da } \\
\text { chaminé }\end{array}$ & $\begin{array}{c}\text { Emissão } \\
\text { MP }\end{array}$ \\
\hline & & UTM $X$ & UTM Y & m & $m$ & $\mathrm{~m}^{3} / \mathrm{h}$ & $\mathrm{Nm}^{3} / \mathrm{h}$ & $\mathrm{m} / \mathrm{s}$ & ${ }^{\circ} \mathrm{C}$ & $\mathrm{m}^{2}$ & $\mathrm{~kg} / \mathrm{h}$ \\
\hline $\mathrm{CH} 1$ & FORNOX & 609045 & 7820074 & 45,00 & 1,10 & 27278,33 & \begin{tabular}{|l|}
18036,17 \\
\end{tabular} & 7,97 & 79,30 & 0,95 & 3,3 \\
\hline $\mathrm{CH} 2$ & FORNOW & 609028 & 7820070 & 45,00 & 1,30 & 25340,67 & 15317,83 & 5,73 & 101,17 & 1,23 & 1,1 \\
\hline $\mathrm{CH} 3$ & FORNOY & 609014 & 7820070 & 45,00 & 1,30 & 55777,83 & \begin{tabular}{|l|}
33851,67 \\
\end{tabular} & 12,62 & 103,37 & 1,23 & 1,3 \\
\hline $\mathrm{CH} 4$ & FORNOZ & 608821 & 7820019 & 50,00 & 1,80 & 163028,67 & 37591,65 & 17,80 & 220,95 & 2,54 & 3,3 \\
\hline
\end{tabular}

Figura 3 - Informações referentes às emissões atmosféricas provenientes das chaminés dos fornos industriais, das empresas A e B. Fonte: SUPRAM-CM. Pedido de Vistas dos processos das empresas A e B. Agosto/2017. Elaboração: Autores (2017).

Segundo a Ecosoft (2014), os fornos utilizados pelas mineradoras em questão são dos tipos rotativo e vertical. O forno rotativo apresenta elevada emissão de particulado, pois detém taxas elevadas de velocidade do ar e aos arrastes das partículas provocadas pela câmara rotativa. O forno vertical, por sua vez, possui as mais baixas emissões de poeiras fugitivas, pois o ar circula em velocidades mais baixas. Segundo a USEPA (1998), os fornos podem utilizar como combustível carvão, gás natural e petróleo. Contudo, os usos de combustíveis fósseis, juntamente com as propriedades do produto dessas mineradoras, podem afetar as emissões de material particulado. 
Ainda de acordo com a Ecosoft (2014), o empreendimento A possui 3 fornos, sendo dois fornos do tipo rotativo e um forno vertical. Já a empresa B possui 4 fornos de calcinação, três são do tipo vertical e um forno do tipo rotativo. Compondo os dados meteorológicos, têm-se a direção e a velocidade dos ventos, parâmetros estes determinantes para a delimitação da pluma de poluição formada, definindo qual a direção preferencial de propagação do material particulado. A Figura 4 foi desenvolvida no software AERMOD, chamada de rosa dos ventos, pois evidencia a região predominante de direção dos ventos para o município estudado.

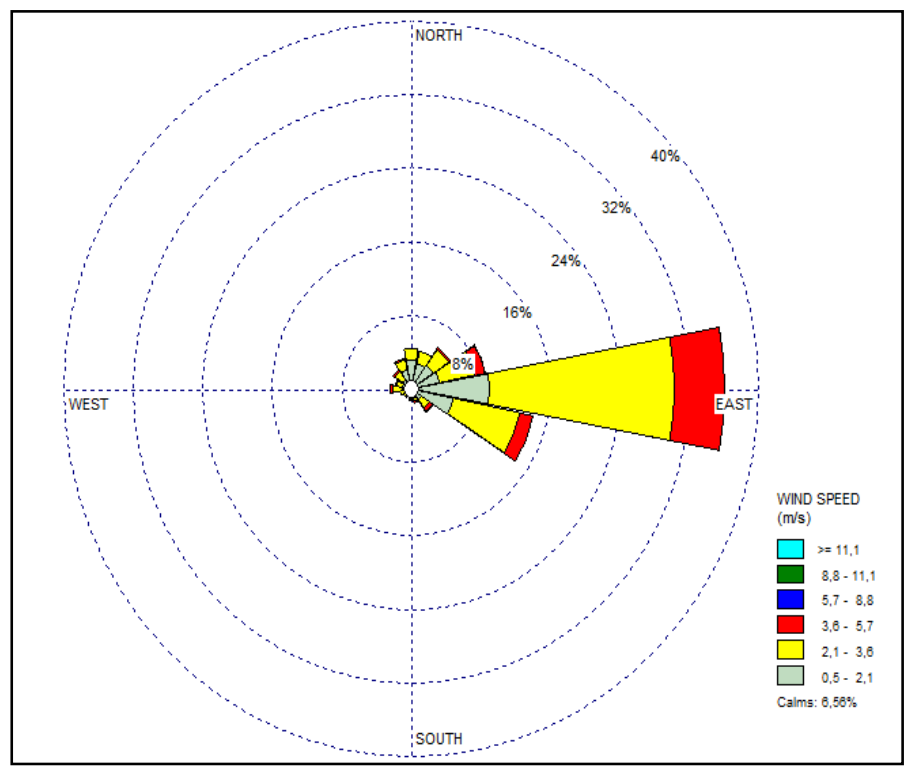

Figura 4 - Rosa dos ventos para o município de São José da Lapa/MG, para o ano de 2016. Elaboração: Autores (2017).

Como se observa pela Figura 3, os ventos são, predominantemente, de origem leste, com também significativas variações para o sudeste. As velocidades médias predominantes são de 2,1 a $3,6 \mathrm{~m} / \mathrm{s}$.

De posse de todos os dados citados e expostos, elaboraram-se as modelagens matemáticas para a dispersão do poluente material particulado em diferentes cenários, sendo estes o período de maior seca (inverno), de maior pluviosidade (verão) e também modelagens referentes a todo ano de 2016, considerando a emissão máxima diária (24h) e a média de cada um destes períodos. Para o período de maior seca, correspondente ao inverno de 2016, na máxima de $24 \mathrm{~h}$, a modelagem da dispersão do material particulado se apresenta conforme a Figura 5. 


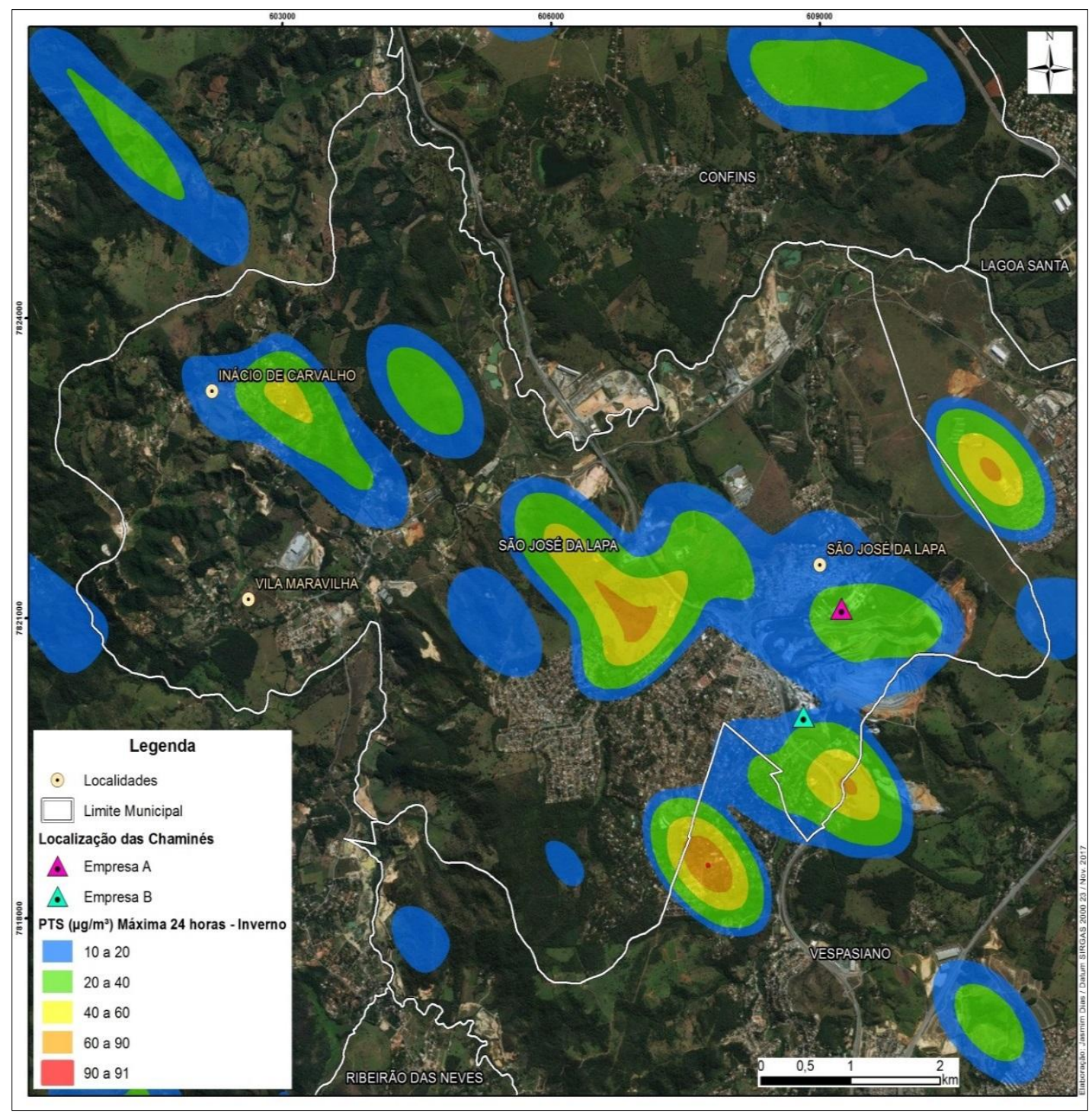

Figura 5 - Modelagem da dispersão de material particulado durante o inverno de 2016. Máxima diária (24h). Elaboração: Autores (2017).

Por se tratar de um período com as menores taxas de precipitação, têmse reduzidos processos de dissolução de poluentes ocorrendo na atmosfera, uma vez que a umidade é menor. Dessa forma, há uma piora na qualidade do ar da região, com concentração máxima em 24 horas entre 90 e $91 \mathrm{\mu g} / \mathrm{m}^{3}$. De acordo com a Resolução CONAMA 03 de 1990, tal concentração classifica-se como de qualidade regular para a qualidade do ar, como previamente exposto na Tabela 2. Observa-se ainda que as plumas de contaminação atmosférica alcançaram áreas de considerável distância das fontes emissoras, atingindo áreas fora do limite municipal. Tal fato indica que a dispersão do material particulado é comprometida neste período estudado. O cenário se demonstra mais crítico em regiões localizadas a oeste das mineradoras, comprovando a relação da direção dos ventos de origem a leste. Considerando todo o período de inverno do ano de 
2016, a dispersão do material particulado se comportou conforme ilustrado no mapa abaixo (Figura 6).

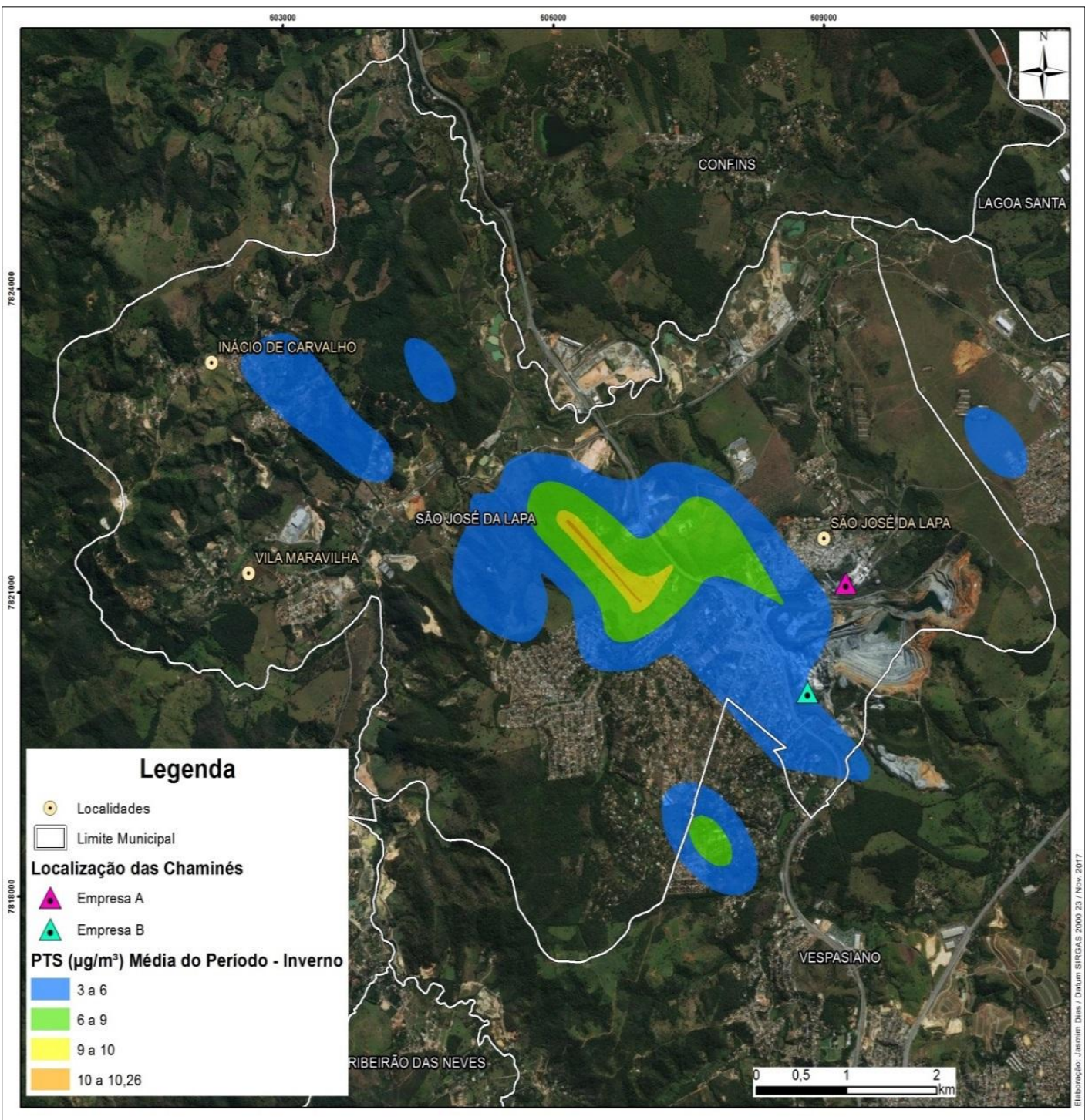

Figura 6 - Modelagem da dispersão de material particulado durante o inverno de 2016. Média geométrica do período inverno de 2016. Elaboração: Autores (2017).

Na modelagem em questão os poluentes ficaram concentrados na porção oeste das fontes emissoras, devido à origem dos ventos a leste. A maior concentração de PTS encontrada para o período analisado foi de $10,26 \mu \mathrm{g} / \mathrm{m}^{3}$. Este valor atende o padrão secundário de qualidade do ar, sendo este o mais restritivo, conforme estabelecido na Resolução CONAMA 03 de 1990. Para o período de maior pluviosidade, que corresponde ao verão de 2016 , o cenário se configura conforme segue (Figura 7). 


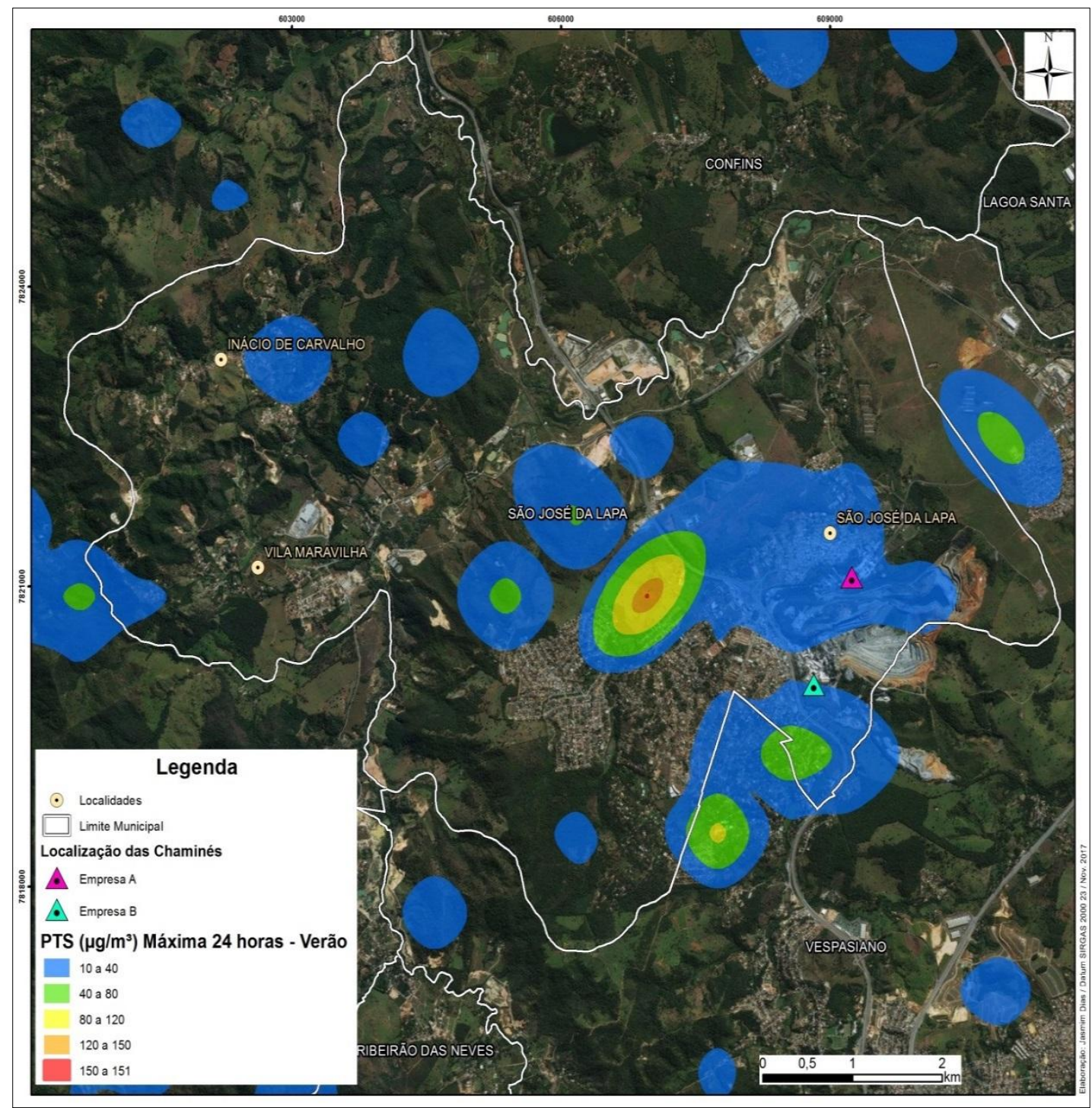

Figura 7 - Modelagem da dispersão de material particulado durante o verão de 2016. Máxima diária (24h). Elaboração: Autores (2017).

A maior concentração de material particulado foi identificada a oeste das fontes emissoras, o que se deu pela direção dos ventos, que têm origem a leste. A concentração máxima em 24 horas atingiu $151 \mu \mathrm{g} / \mathrm{m}^{3}$, o que se enquadra como padrão primário da Resolução CONAMA 03/90, porém, tem valor superior ao definido para o padrão secundário. Apesar da qualidade do ar se apresentar, majoritariamente, melhor durante o verão, dependendo das condições meteorológicas, como vento e temperatura, pode-se alcançar níveis mais críticos que comprometam a mesma. Ademais, devem-se ponderar sobre possíveis falhas advindas da modelagem, que pode ter resultado neste pico na concentração. Contudo, considerando a abrangência da pluma de maior concentração, esta é pontual, não atingindo, assim, maiores áreas. A figura 8 apresenta como se comportou a dispersão no período de verão analisado no ano de 2016. 


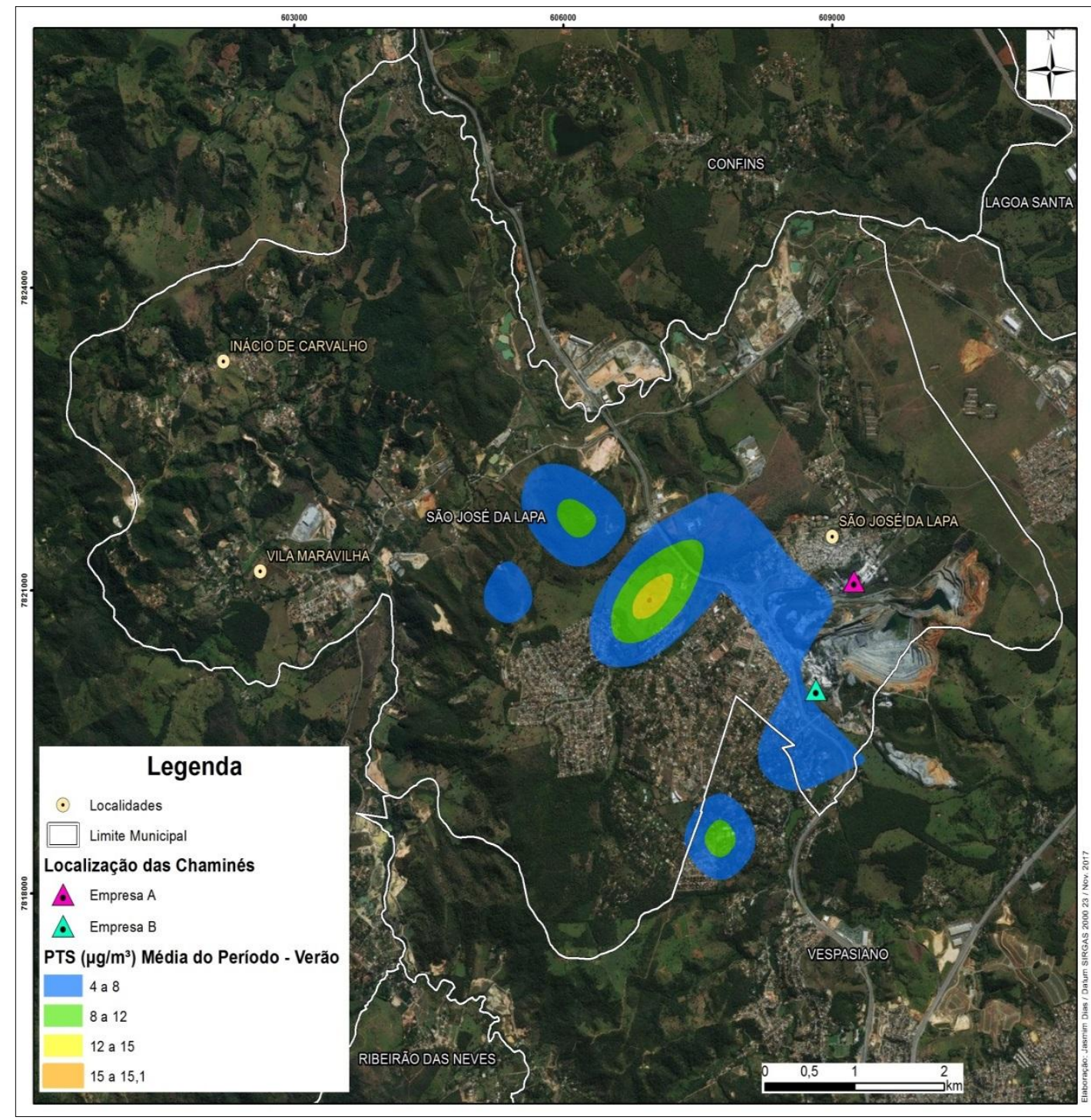

Figura 8 - Modelagem da dispersão de material particulado durante o verão de 2016. Média geométrica do período verão de 2016. Elaboração: Autores (2017).

Assim como no cenário apresentado anteriormente, houve uma concentração maior de material particulado a oeste das fontes emissoras, devido a direção dos ventos. Pode-se observar ainda que as plumas de poluição apresentam menor abrangência espacial, com concentrações baixas de PTS na atmosfera. Desta forma, pode-se inferir que a interação entre o efluente emitido (pelas chaminés das empresas) e a atmosfera ocorreu de forma satisfatória, visto que a maior concentração encontrada para o período foi $15,1 \mu \mathrm{g} / \mathrm{m}^{3}$, o que atende o padrão mais restritivo, o padrão secundário da Resolução CONAMA 03 de 1990. Finalmente, apresentam-se as modelagens atmosféricas considerando todo o ano de 2016, para a máxima de 24 horas e a média geométrica anual. No que se refere à máxima diária de todo o período, tem-se a pluma de dispersão do PTS se comportando conforme a Figura 9. 


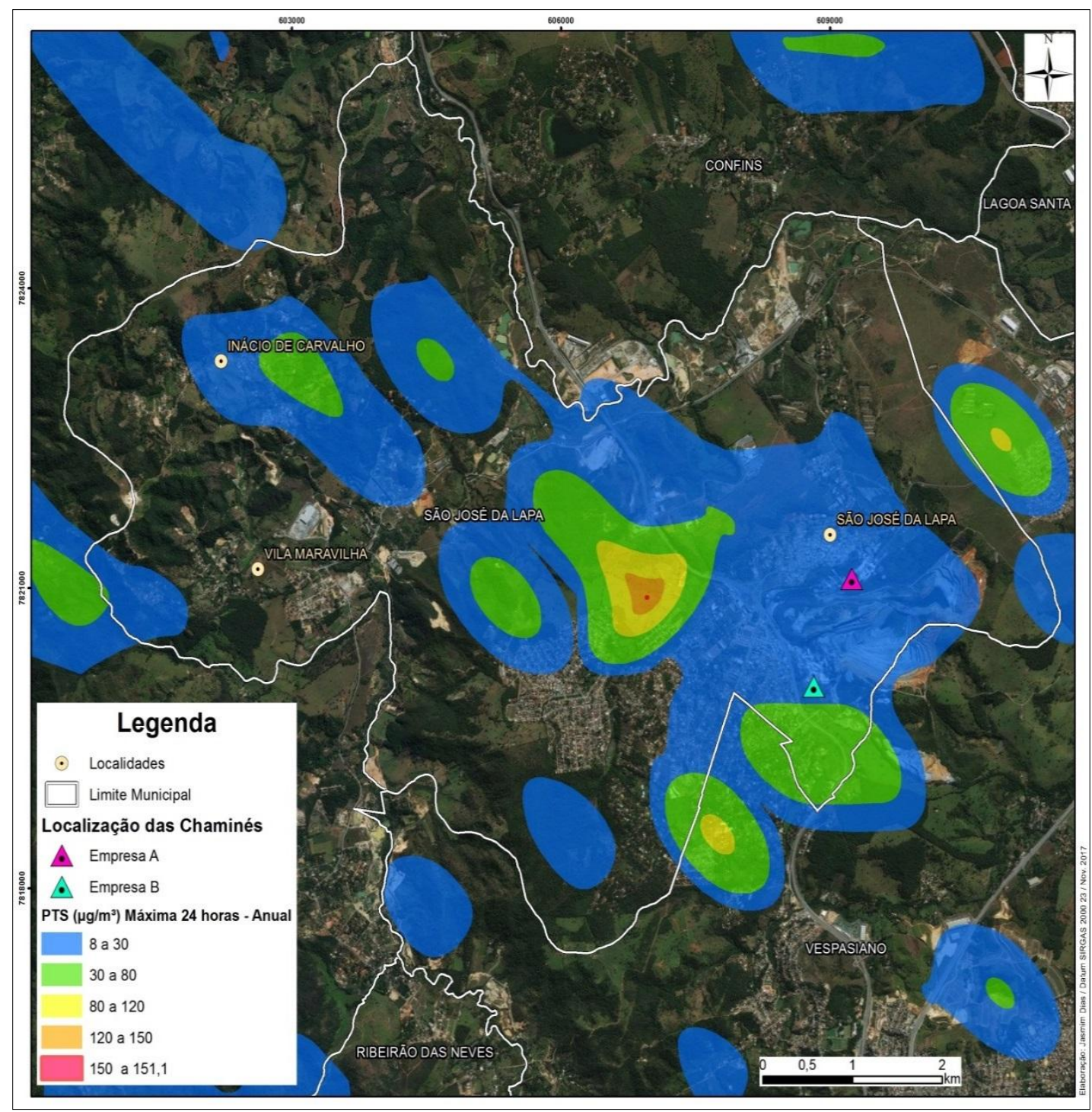

Figura 9 - Modelagem da dispersão de material particulado durante 2016. Máxima de 24h. Elaboração: Autores (2017).

Neste cenário, percebe-se que as emissões de material particulado, provenientes das mineradoras, alcançam áreas longínquas, com diferentes concentrações ao longo da área de dispersão. Levando-se em consideração uma análise do perfil morfológico da região, percebe-se que as elevações topográficas das porções a oeste das fontes emissoras tendem a funcionar como barreira orográfica ou anteparo, exercendo a clássica função de "bacia aérea", onde o poluente atmosférico fica retido. Tal elemento orográfico justifica as concentrações dadas ao longo de todas as análises realizadas.

Como este modelo corresponde a todo o ano de 2016, ressalta-se novamente que a modelagem mostra a maior concentração observada na máxima em 24 horas, sendo esta $151,1 \mu \mathrm{g} / \mathrm{m}^{3}$, ultrapassando o padrão secundário $\left(150 \mu \mathrm{g} / \mathrm{m}^{3}\right)$ definido para este poluente, de acordo com a CONAMA 03/90, conforme apontado previamente. Tal concentração é ainda classificada 
como regular para a qualidade do ar. Apesar dos valores com picos máximos de concentração terem sido registrados superiores ao padrão secundário, entendese que os mesmos não possuem representatividade espacial enquanto dimensão da pluma, visto que estes são de pequena abrangência. Por sua vez, os valores de concentração mais representativos, que incidem em maior área espacial, não indicam comprometimento à qualidade do ar, apresentando concentrações que variam de 8 a $30 \mu \mathrm{g} / \mathrm{m}^{3}$. Para as regiões contrárias à direção dos ventos, bem como àquelas de relevo menos acidentado, têm-se menores concentrações de poluentes atmosféricos.

Para a média geométrica anual, a dispersão do poluente PTS se deu conforme ilustrado na Figura 10.

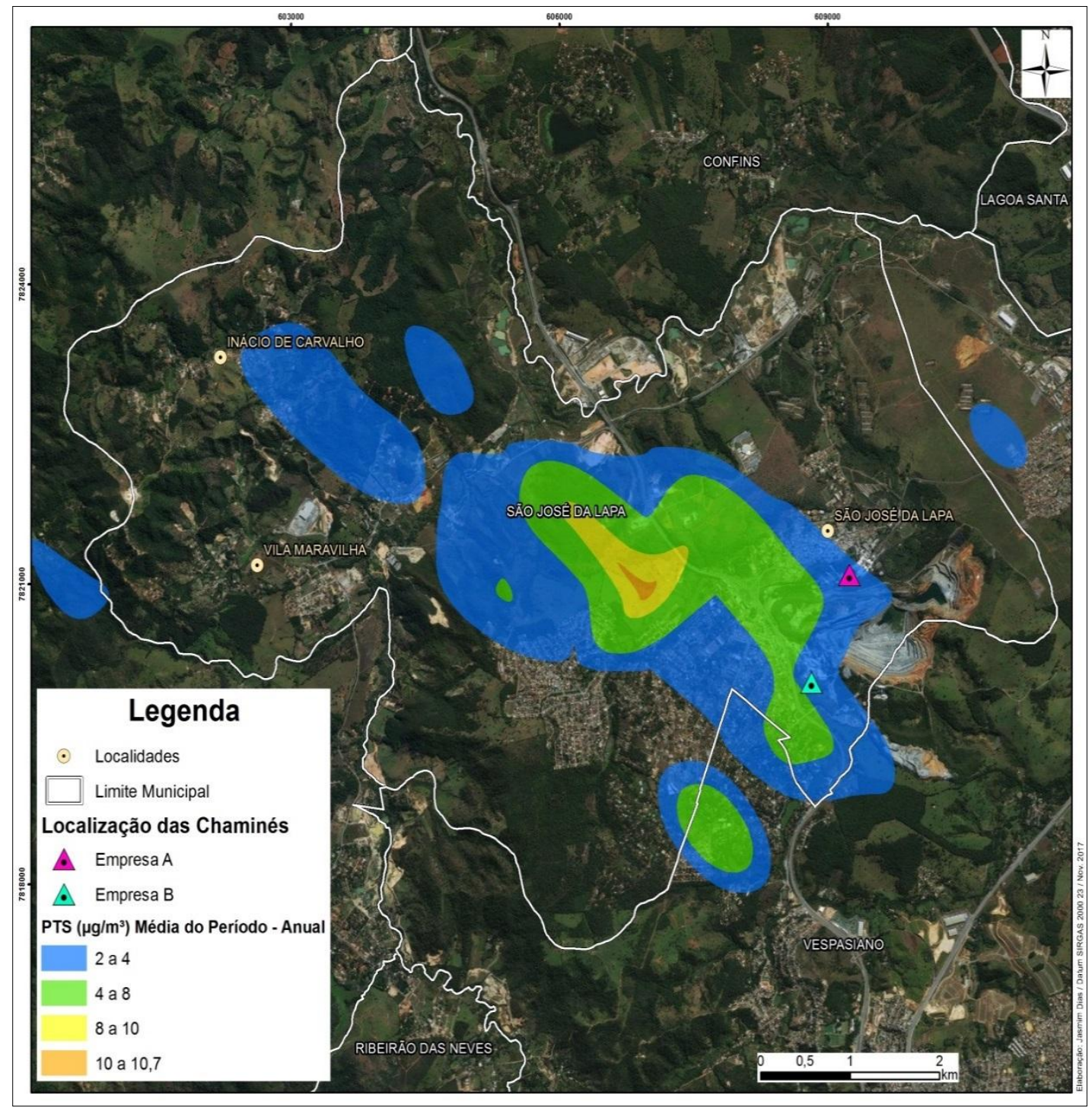

Figura 10 - Modelagem da dispersão de material particulado durante 2016. Média geométrica anual. Elaboração: Autores (2017). 
Pode-se observar que a diluição do material particulado na atmosfera ocorreu de forma significativa, visto que a maior concentração de PTS identificada para o período anual analisado foi de $10,7 \mu \mathrm{g} / \mathrm{m}^{3}$, enquadrando-se desta forma à legislação vigente. Ademais, identificou-se que a concentração de 2 a $8 \mu \mathrm{g} / \mathrm{m}^{3}$ esteve presente em uma área significativa do município de São José da Lapa.

\section{CONSIDERAÇÕES FINAIS}

Como observado nos modelos de dispersão do material particulado apresentados, as altas taxas de poluição atmosféricas, o relevo local e as condições meteorológicas, contribuem para um cenário delicado para a qualidade do ar no município de São Jose da Lapa.

Porém, há de se ressaltar ainda que as modelagens ora apresentadas correspondem apenas às chaminés das mineradoras $A$ e $B$, visto que estas são as fontes mais representativas e confiavelmente quantificáveis. Isto é, não foram consideradas todas as fontes possíveis de emissão de poluentes. Para a empresa $A$, foram estudadas as emissões das chaminés dos 3 fornos, porém, não considerou-se a emissão proveniente da chaminé da hidratação, nem das 2 chaminés dos processos de moagem, dos dois pontos de Recupol e das 3 chaminés do processo de silo presentes nesta mineradora. Já para empresa $B$, além das chaminés dos 4 fornos aqui quantificados, têm-se ainda uma chaminé da hidratação, e 5 chaminés dos pontos de moagem dessa empresa, que não foram consideradas neste estudo.

Dessa forma, para futuros trabalhos, recomenda-se a quantificação de todas as fontes fixas instaladas nas mineradoras. De forma a ter um estudo ainda mais fidedigno, é importante ainda quantificar as emissões fugitivas, provenientes da circulação de veículos, bem como da suspensão de poeira de áreas abertas. Neste sentido, ter-se-á uma modelagem mais real da dispersão do material particulado neste município.

Considerando todos estes fatores, os índices de qualidade do ar, possivelmente, alcançarão valores ainda mais altos, demandando, assim, ações mais incisivas para o controle da poluição atmosférica local. Neste sentido, pode-se propor, como medidas básicas, a aspersão de água mais frequente na região e adensamento da cortina arbórea ao redor das mineradoras, de forma a reter mais materiais particulados.

Recomenda-se ainda que seja realizado um estudo visando identificar a eficácia dos controles de poluentes instalados nas chaminés empregadas na empresa. De acordo com a Comissão de Cooperação Ambiental da América do Norte - Commission for Environmental Cooperation (2005), para o controle de materiais particulados, utiliza-se coletores mecânicos, precipitadores eletrostáticos, filtros de manga ou depuradores úmidos. Cada alternativa de controle tem suas respectivas limitações, sendo necessário, assim, avaliar para cada cenário, qual opção se torna mais eficiente. 


\section{REFERÊNCIAS}

Brasil. Ministério do Meio Ambiente. Conselho Nacional do Meio Ambiente. Resolução CONAMA No 003, de 28 de junho de 1990. Dispõe sobre padrões de qualidade do ar previstos no PRONAR.

Companhia Ambiental do Estado de São Paulo. Relatório de qualidade do ar no Estado de São Paulo: relatório técnico. São Paulo: CETESB, 2015.

Commission for Environmental Cooperation (CEC) of North America. Best Available Technology for Air Pollution Control: Analysis Guidance and Case Studies for North America. MJ Bradley \& Associates, Quebec/Canada, p.20-21, 2005.

Ecosoft Soluções Ambientais. Ical Indústria de Calcinação Ltda; Mineração Belocal Ltda. Estudo de Dispersão Atmosférica e Revisão da Rede de Monitoramento da Qualidade do Ar de São José da Lapa/MG, 2014, 91p.

Fundação Estadual do Meio Ambiente de Minas Gerais. Monitoramento da Qualidade do Ar na Região Metropolitana de Belo Horizonte - Ano Base de 2013. Relatório Técnico. Belo Horizonte: FEAM, 2016.

Fundação Estadual de Proteção Ambiental do Rio Grande do Sul. Índice de Qualidade do Ar (IQAr). Porto Alegre: FEPAM, 2017.

Gomes, J.F.P. Poluição Atmosférica: Um Manual Universitário. Portugal: Publindústria, 2010, 77p.

Guarieiro, L.L.N.; Vasconcellos, P.C.; Solci, M.C. Poluentes Atmosféricos Provenientes da Queima de Combustíveis Fósseis e Biocombustíveis: Uma Breve Revisão. Rev. Virtual Quím., 3(5), 434-445, 2011.

Instituto Brasileiro de Geografia e Estatística. Mapa de Clima do Brasil. Rio de Janeiro: IBGE, 2005.

Instituto Brasileiro de Geografia e Estatística. Cidades: São José da Lapa/MG. Disponível em: <https://cidades.ibge.gov.br/v4/brasil/mg/sao-jose-dalapa/panorama>. Acesso em: 29 jul. 2017.

Jacomino, V.M.F., Barreto, A.A., Tavares, F.V.F., Peixoto, C.M., Rodrigues, P.C.H. Avaliação da qualidade do ar em um polo produtor de ferro-gusa. Eng. Sanit. Ambient, 14(4), 511-520, 2009.

Lakes Environmental. AERMOD. 2014. Disponível em: <https://www.weblakes.com/products/aermod/>. Acesso em: 24 nov. 2017.

Melo, J.; Lima, E.; Gimenes, M. Estudo Computacional das Emissões e Dispersões Atmosféricas dos Processos KRAFT de Produção de Celulose: Avaliação da Qualidade do Ar. Eng. Sanit. Ambient, 21(2), 233-240, 2016.

United States Environmental Protection Agency. Air Quality Index (AQI) Basics. USEPA, 2017.

United States Environmental Protection Agency. Our Nation's Air: Status and Trends Through 2015. USEPA, 2015.

United States Environmental Protection Agency. Emission Factor Documentation for AP-42: Mineral Products Industry. 5a Edition. Volume I. Chapter 11. Section: 11.17. USEPA, 1998. 